\title{
Eimeria ninakohlyakimovae (Apicomplexa: Eimeriidae) de caprinos leiteiros de um criatório na microrregião do Rio de Janeiro: aspectos morfobiológicos
}

\author{
Eimeria ninakohlyakimovae (Apicomplexa: Eimeriidae) of goats from \\ a dairy farm in microrregion of Rio de Janeiro: morphological \\ and biological aspects
}

\author{
Walter Leira Teixeira Filho, ${ }^{*}$ Rita de Cássia Alves Alcantara de Menezes, ${ }^{*}$ Carlos Wilson Gomes Lopes*
}

\begin{abstract}
Resumo
Com o objetivo de determinar a presença de Eimeria ninakohlyakimovae, assim como os aspectos morfobiológicos relacionados a essa espécie nos caprinos leiteiros de um criatório na microrregião do Rio de Janeiro, utilizou-se um sistema de criação semi-intensivo localizado no município de Maricá. Foram formados dois grupos de animais portadores de infeç̧ão natural: 65 jovens com até 180 dias de idade e 314 adultos. Foram coletadas 379 amostras individuais de fezes para verificar a presença de oocistos dessa espécie e o tempo de esporulação foi observado nas temperaturas de $20,33 \pm 1,24$ (temperatura ambiente); 18,27 e $32^{\circ} \mathrm{C}$. Observou-se pleomorfismo dessa amostra de E. ninakohlyakimovae e o tempo de esporulação dos oocistos foi menor nas temperaturas mais elevadas.
\end{abstract}

Palavras-chave: Eimeria ninakohlyakimovae; morfologia; tempo de esporulação; caprinos leiteiros.

\begin{abstract}
This study was carried out to verify and characterize E. ninakohlyakimovae in dairy goats. Animals were breeding at Municipality of Maricá, in the microrregion Rio de Janeiro, from the State of Rio de Janeiro. In a total of $\mathbf{3 7 9}$ fecal samples of two groups of animals, 65 kids until 180 days of age and 314 adults, males and females were examined. The sporulation time was observed at four different temperatures, as followed: $20,33 \pm 1,24$ (environment temperature), 18,27 and $32^{\circ} \mathrm{C}$. A certain pleomorphism was verified in oocysts of this strain of E. ninakohlyakimovae. The sporulation process took place more rapidly at 27 and $32^{\circ} \mathrm{C}$.
\end{abstract}

Keywords: Eimeria ninakohlyakimovae, morphology, sporulation time, dairy goats.

\section{Introdução}

Durante longo tempo, devido à similaridade morfológica, oocistos de Eimeria de caprinos e ovinos foram considerados como pertencentes à mesma espécie. Atualmente sabese que existe uma alta especificidade em relação ao hospedeiro e que essa é uma característica importante para auxiliar na diferenciação das espécies do gênero Eimeria (Musaev, 1970). O tamanho dos oocistos, suas estruturas externa e interna, como também o tempo de esporulação, são consideradas características importantes para o diagnóstico das espécies deste gênero de parasitas de pequenos ruminantes (Long e Joyner, 1984).

Rebanhos de caprinos leiteiros geralmente apresentam grande morbidade devido à coccidiose, principalmente na forma assintomática. Eimeria ninakohlyakimovae Yakimoff e Rastegaieff, 1930 vem sendo considerada como a espécie do gênero mais patogênica para caprinos (Craig, 1986) e tem sido freqüentemente identificada com altas prevalências em todas as regiões estudadas (Magi et al., 1986; Bomfim e Lopes, 1994).

O presente estudo teve como objetivo identificar possíveis variações intra-específicas que possam interferir no diagnóstico dessa espécie, assim como fornecer dados biológicos quanto ao tempo de esporulação dos oocistos.

\section{Material e métodos}

Os 379 animais utilizados pertenciam a uma caprinocultura de propriedade particular, localizada no município de Maricá, na microrregião do Rio de Janeiro (IBGE, 1996), Estado do Rio de Janeiro.

O criatório era composto por caprinos mestiços e puros das raças Alpina e Toggenburg, naturalmente infectados por $E$.

\footnotetext{
* Departamento de Parasitologia Animal, Instituto de Veterinária da Universidade Federal Rural do Rio de Janeiro, Seropédica, RJ, Brasil, $23890-000$. cppasv@ufrrj.br
} 
ninakohlyakimovae e foram agrupados da seguinte forma: animais com até 180 dias de idade e adultos, independentemente do sexo e estado fisiológico. $O$ rebanho era submetido ao sistema de manejo semi-intensivo e recebia sal mineral e água à vontade.

Foram coletadas amostras individuais de fezes, sendo 65 de caprinos jovens e 314 de animais adultos. O material fecal foi processado pela técnica de centrífugo-flutuação de acordo com Menezes e Lopes (1995), para verificar a presença de oocistos de E. ninakohlyakimovae. Em seguida, homogeneizaram-se em meio aquoso as fezes oriundas de animais de um mesmo grupo e adicionou-se bicromato de potássio a 2,5\% para que ocorresse a esporulação dos oocistos e sua posterior identificação, baseada na forma, medidas e estruturas internas dos oocistos. Para verificar 0 tempo de esporulação dos oocistos, o material fecal proveniente de cada grupo foi submetido às seguintes temperaturas: $20,33 \pm 1,24$ (temperatura ambiente), 18,27 e $32^{\circ} \mathrm{C}$. As observações foram feitas em intervalos de seis horas até a obtenção de no mínimo $80 \%$ dos oocistos esporulados. Foi feita a análise de variância e o teste T dos resultados obtidos.

\section{Resultados e discussão}

Para identificação dos oocistos tomaram-se como base os trabalhos de Levine (1985) para características morfológicas e os de Mussaev (1970) e Norton (1986) para os aspectos biológicos.

Os oocistos observados (Figura 1) tiveram forma elipsoidal à subesférica, com índice morfométrico médio de $1,24 \pm 0,07 \mu \mathrm{m}$ para animais jovens e $1,14 \pm 0,07 \mu \mathrm{m}$ para animais adultos,
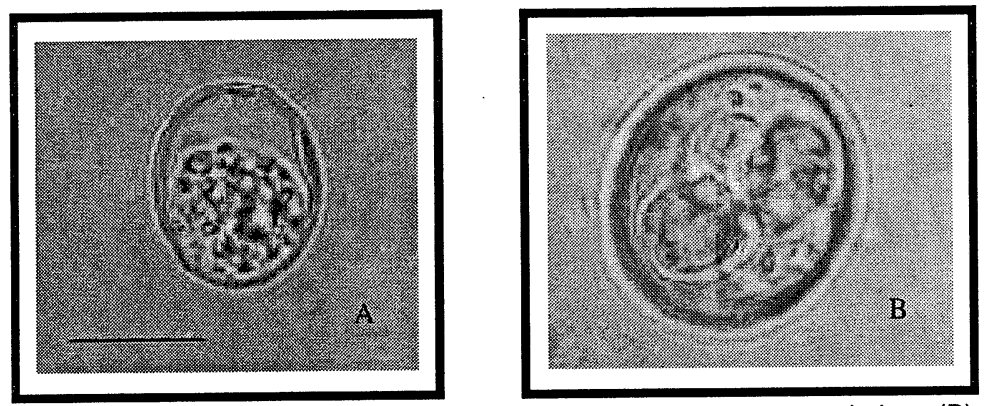

Figura 1 - Oocistos de Eimeria ninakohlyakimovae. (A) Não esporulado e (B) esporulado. Solução saturada de açúcar $(3 / 4 / 4=10 \mu \mathrm{m})$.

apresentando diferença significativa entre ambos. Entretanto, a forma observada está em concordância com os trabaIhos de Pires e Lopes (1985), Levine (1985). Menezes e Lopes (1996) verificaram que oocistos dessa espécie, provenientes da região serrana do Estado do Rio de Janeiro, tinham forma subesférica à elipsoidal; no entanto, o índice morfométrico encontrado para os oocistos obtidos de animais adultos foi muito maior. Já Hassum e Menezes (2000), em estudo com caprinos jovens do município de Saquarema, região litorânea do Estado do Rio de Janeiro, observaram oocistos $E$. ninakohlyakimovae de forma oval, embora o tamanho dos oocistos tenha sido próximo ao do presente estudo.
Na Tabela 1 estão relacionadas as médias e o desvio-padrão das medidas de 100 oocistos oriundos de animais jovens e adultos. Apesar de se observar diferença significativa entre 0 diâmetro maior dos oocistos dos animais jovens e adultos, esses valores concordam com os resultados encontrados por Pires e Lopes (1985), Bomfim e Lopes (1994) e Hassum e Menezes (2000). Já Menezes e Lopes (1996) observaram que os oocistos eliminados pelos jovens foram menores quando comparados aos deste estudo. Mesmo ocorrendo variações no tamanho dos oocistos, o seu índice morfométrico tem-se mantido constante (Fayer, 1980, Long e Joyner, 1984), sendo que essas modificações podem ser causadas por vários fatores, tais como: estado imune dos animais, grau de infecção e período de patência (Magi et al., 1986).

Tabela 1 - Medidas de 100 oocistos e esporocistos Eimeria ninakohlyakimovae de caprinos leiteiros jovens e adultos de um criatório na microrregião do Rio de Janeiro

\begin{tabular}{lccccc}
\hline Idade & \multicolumn{2}{c}{ Diâmetro dos oocistos $(\mu \mathrm{m})$} & & \multicolumn{2}{c}{$\begin{array}{c}\text { Diâmetro dos } \\
\text { esporocistos }(\mu \mathrm{m})\end{array}$} \\
\cline { 2 - 3 } \cline { 5 - 6 } & Maior $^{\mathrm{a} b}$ & Menor $^{\mathrm{a}}$ & & Maior $^{\mathrm{a}}$ & Menor $^{\mathrm{a}}$ \\
\hline Jovens & $24,69 \pm 1,38$ & $19,90 \pm 1,21$ & & $10,59 \pm 0,59$ & $6,93 \pm 0,81$ \\
Adultos & $22,55 \pm 1,40$ & $19,68 \pm 1,21$ & & $10,24 \pm 1,08$ & $6,55 \pm 0,37$ \\
\hline
\end{tabular}

a Medidas em $\mathrm{x} \pm$ Dsd

b $P \leq 0,01$

A micrópila na maioria das vezes foi indistinta, tanto nos oocistos obtidos de animais jovens como nos de adultos. A parede do oocisto era constituída por duas membranas de aspecto liso e, de coloração marrom-amarelada, medindo de espessura $1,46 \pm 0,15 \mu \mathrm{m}$ para animais jovens $e$ $1,37 \pm 0,14 \mu \mathrm{m}$ para adultos, concordando com os valores $(1$ a $5 \mu \mathrm{m})$ encontrados por Yakimoff e Rastegaieff (1930), e bem mais espessa que o encontrado por Menezes e Lopes (1996).

Os esporocistos apresentaram forma oval alongada, com corpo de "Stieda". Quanto às dimensões, não se observou diferença significativa entre 0 material oriundo de animais jovens e adultos, que foram compatíveis com o observado por Hassum e Menezes (2000), embora não estejam de acordo com os encontrados por Lima (1980) e sejam maiores que os observados por Menezes e Lopes (1996).

O tempo de esporulação foi verificado a intervalos de seis horas (Tabela 2) e o processo obteve mai-

Tabela 2 - Tempo de esporulação, em intervalos de horas, dos oocistos de Eimeria ninakohlyakimovae obtidos de caprinos leiteiros de um criatório na microrregião do Rio de Janeiro

\begin{tabular}{cccccc}
\hline & \multicolumn{2}{c}{ Jovens } & & \multicolumn{2}{c}{ Adultos } \\
\cline { 2 - 3 } \cline { 5 - 6 } Temperatura ${ }^{\circ} \mathrm{C}$ & Esporocistos & Esporozoítas & & Esporocistos & Esporozoítas \\
\hline 18,00 & $30-72$ & $60-84$ & & $30-48$ & $54-72$ \\
$20,33 \pm 1,21^{\text {a }}$ & $24-54$ & $36-78$ & & $24-42$ & $30-60$ \\
27,00 & $18-48$ & $30-66$ & & $24-54$ & $24-66$ \\
32,00 & $12-48$ & $12-72$ & & $18-36$ & $42-54$ \\
\hline
\end{tabular}


or êxito nas temperaturas de 27 e $32^{\circ} \mathrm{C}$, concordando com a faixa de temperatura entre 27 e $29^{\circ} \mathrm{C}$, considerada como ideal para a esporulação de várias espécies (Long e Joyner, 1984, Norton, 1986, Menezes e Lopes, 1996).

Foi possivel verificar que nas temperaturas mais elevadas 0 processo de esporulação teve início mais rapidamente. Entretanto, prolongou-se mais do que na temperatura de $20,33 \pm 1,24$ e $18^{\circ} \mathrm{C}$ para ser totalmente concluído. Possivelmente esse fato se deve ao efeito deletério da temperatura $\left(32^{\circ} \mathrm{C}\right)$, como comentado por Marquardt (1960), que verificou a inibição da esporulação em temperaturas superiores a $35^{\circ} \mathrm{C}$. Em relação aos resultados obtidos nas temperaturas de 27 e $32^{\circ} \mathrm{C}$ com material proveniente de caprinos adultos, é importante ressal-

\section{Referências}

BOMFIM, T. C. B. do, LOPES, C. W. G. 1994. Levantamento de parasitos gastrintestinais em caprinos da região serrana do estado do Rio de Janeiro. Rev. Bras. Parasitol. Vet., v. 3, p. 119-124.

CRAIG, M. Epidemiology and control of coccidia in goats. Vet. Clin. North Am./Food An. Pract., 2, p. 389-395, 1986.

FAYER, R. Epidemiology of protozoan infections: the coccidia. Vet. Parasitol., v. 6, p. 75-103, 1980.

HASSUM, I. C., MENEZES, R. de C. A. A. de. Estudo morfológico das espécies Eimeria alijevi, E. arloingi e E. ninakohlyakimovae de caprinos leiteiros jovens de um criatório na microrregião Lagos, RJ. Rev. Bras. Ciênc. Vet., v. 7, p. 97-99, 2000.

IBGE. Censo Agropecuário. Rio de Janeiro. 1996. http:// www.ibge.gov.br/informações/censo96/Agro. 21set.1998.

LEVINE, N. D. Veterinary Protozoology. lowa State University Press. Ames. 414 p., 1985.

LIMA, J. D. Prevalence of coccidia in domestic goats from Illinois, Indiana, Missouri and Wisconsin. Int. Goat and Sheep Res., v. 3, p. 234$241,1980$.

LONG, P. L., JOYNER, L. P. Problems in the identification of species of Eimeria. J. Protozool., v. 31, p. 535-541, 1984.

MAGI, M., CAMPO, M., MALLOGGI, M., SBRANA, L., CASAROSA, L. The Coccidia of the domestic goats (Capra hircus) in Italy. Ann. Fac. Med. Vet. Pisa, v. 39, p. 185-188, 1986. tar que o estudo foi feito com amostras ao acaso, coincidindo com a ausência de oocistos contendo esporocistos ou esporozoítas em determinados horários de observação.

Foi possível caracterizar morfológica e biologicamente a espécie estudada como $E$. ninakohlyakimovae, mas observou-se diferença na forma e medidas dos oocistos obtidos de caprinos jovens e adultos, demonstrando um certo grau de pleomorfismo. Para a amostra de E. ninakohlyakimovae obtida neste criatório a temperatura de $32^{\circ} \mathrm{C}$ não foi adequada para a esporulação dos oocistos, contrastando com a cepa da mesma espécie estudada por Menezes e Lopes (1996) na microrregião serrana fluminense, localizada no mesmo estado.

MARQUARDT, W. C. Effect of hight temperature on sporulation of Eimeria zurnii. Exp. Parasitol., v. 10, p. 58-65, 1960.

MENEZES, R. de C. A. A. de, LOPES, C. W. G. Epizootiologia da Eimeria arloingiem caprinos na microrregião serrana fluminense, Rio de Janeiro, Brasil. Rev. Univ. Rural, Sér. Ciênc. da Vida, v. 17, p. 5-12, 1995.

. Aspectos morfobiológicos de Eimeria ninakohlyakimovae (Apicomplexa: Eimeriidae) em caprinos leiteiros na microrregião serrana fluminense, Rio de Janeiro. Rev. Bras. Med. Vet., v. 18, p. 212-215, 1996.

MUSAEV, M. A. Especificidade dos coccídios aos seus hospedeiros e algumas questões de sua taxonomia. Izv. Akad. Nauk. Azerbaijanski - SSR, v. 2, p. 52-61. 1970. (Tradução de LIMA, J. D., Univ. Fed. M. Gerais, Belo Horizonte, MG; datilograf. 11 p.).

NORTON, C. C. Coccidia of the domestic goat Capra hircus, with notes on Eimeria ovinoidalis and E. bakuensis (syn. E. ovina) from the sheep Ovis aries. Parasitology., v. 92, p. 279-289, 1986.

PIRES, P. P., LOPES, C. W. G. Espécies de Eimeria (Apicomplexa: Eimeriidae) em caprinos anglo-nubianos no Estado do Rio de Janeiro. Arq. Univ. Fed. Rur. Rio de J., v. 8, p. 71-79, 1985.

YAKIMOFF, W. L., RASTEGAIEFF, E. F. Zur frage uber Coccidien der Ziegen. Arch. Protistenkd. v. 70, p. 185-191, 1930. In: VIEIRA, L. da S. 1996. Eimeria ninakohlyakimovae Yakimoff \& Rastegaieff, 1930 emen. Levine, 1961. Biologia, ultraestrutura e aspectos clínicos da infecção em caprinos experimentalmente infectados. 135p. Tese (Doutorado) - Universidade Federal de Minas Gerais. 